- Moving the management of volunteers to our services/ departments

- Encompassing volunteers from Retail \& Fundraising

- Increasing the variety of roles to match need

- Developing a more highly trained volunteer workforce

- Improving ongoing support and communication

Our approach was to regard 'Emotional competence' to be the highest context of training and preparing volunteers and we have designed a baseline programme which we have named 'Oyster' training. The amount of training corresponds to the emotional complexity of the work and then the service itself undertakes further supervision, mentoring and training to assist the volunteer in to the specific role. At the higher end this is work undertaken by volunteers who are working for our new Loss \& Transition service, which provides pre and post bereavement support. We have learnt that for the transition of volunteers to services to work effectively it is important to structure the services to lead on particular volunteer roles; for example new Loss \& Transition Co-ordinators developed from a Social Work re-structure and a Front of House Volunteer Lead from an Admin and Facilities re-structure. The hearts and minds part of the development both for staff and volunteers requires regular face to face contact; relationship being an important underpinning of the change. This is all still work in progress and the development of the capacity for volunteers to co-ordinate themselves and support each other is the next important step.

\section{P35 VOLUNTEER LINE MANAGEMENT TRAINING AND SUPPORT}

Louise McCartney. Douglas Macmillan Hospice, Stoke on Trent, England

\subsection{6/bmjspcare-2013-000591.57}

Introduction "Volunteers are vital to the future of Hospice care", as are those who manage volunteers.

The management of volunteers and acceptance of responsibilities was inconsistent across our Hospice: limited allocated line mangers; fear of managing situations and volunteers "wrong". It was essential to develop a line manager programme, training and support as volunteer numbers increased and to effectively support our community of $900+$ volunteers. The aims:

- Delegate responsibility of volunteers to departments e.g. training

- Engage volunteers at departmental level

- Develop skills to manage volunteers effectively

- Adherence to policies and procedures

Methods Multi-step approach ensured the programme was manageable:

1. Redesign and create policies and procedures, e.g. resolving difficulties, through consulting with staff and volunteers

- Outlining responsibilities of line managers, volunteers and Voluntary Services (VS)

- Provide clear structure to address and manage problems

2. Establish role descriptions allocating volunteer line management departmentally

3. Line manager training

- External trainer

- VS led sessions

4. Accessible information
- Departmental folders

- VS intranet page
5. Bi-monthly line manager meetings: maintain volunteer data, discuss initiatives and problems

6. Annual line managers training/updates

7. New staff inductions

Conclusion Successes:

- Clear management within agreed procedures and responsibilities

- Departmental volunteer line managers allocated

- Volunteer training and development of roles has increased due to increased knowledge and confidence of line managers working with volunteers

- Volunteer engagement and commitment has been fostered through good people management and treating volunteers fairly, resulting in increased volunteer numbers and higher retention rates

- Volunteer line managers seek advice on how to address problems and manage volunteers as opposed to expecting VS to deal with all volunteer requirements

- Reduced dependence on VS enabling focus to be on data maintenance and strategy

- Created a peer support network amongst line managers

Due to the successes and learning from the experience we are undertaking the process for remote retail managers.

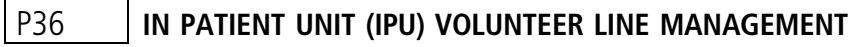 AND EXPANSION OF VOLUNTEER ROLES AND RESPONSIBILITIES}

Carol Lane, Jeanette McCartney, Louise McCartney. Douglas Macmillan, Stoke on Trent, England

\subsection{6/bmjspcare-2013-000591.58}

Introduction It was recognised, at the Douglas Macmillan Hospice $(\mathrm{DMH})$, that there was a need to diversify the role of IPU volunteers to support the clinical services. Previous attempts to increase the roles and responsibilities of volunteers on the IPU failed due to: lack of line management, staff perception of volunteer competencies and fear of the loss of staff roles. An IPU volunteer co-ordinator (VC) was appointed to develop the role and to work within best practise line management, as defined and implemented by Voluntary Services across the hospice.

Methods A Band 3 Health Care Support Worker (HCSW) was seconded from the IPU initially for 37.5 hours/week for 3 months and 15hours/week subsequently into the role of VC. The HCSW retained clinical hours to maintain clinical skills. The VC worked in consultation with the IPU team to identify additional volunteer roles. The following were identified:

- Care: e.g. assistance with personal hygiene, nutrional needs

- Companion: companionship to patients

- Sitter: being with patients who require supervision e.g. patients who are anxious

- Escort: escorting hospital appointments

The IPU team were involved in the training and competency process so that they took sownership and responsibility for new volunteers. The VC is responsible for recruitment, training, rostering and appraisal of the volunteers. The staff on the IPU have access to the volunteer details so that they can access the volunteer, if needed, outside of the rostered hours.

Conclusion This role has been well received:

Successes 